\title{
Le Cheng, King Kui Sin \& Anne Wagner (eds) 2014. The Ashgate Handbook of Legal Translation. Law, Language and Communication. Farnham: Ashgate Publishing Company. 325 pages. ISBN 9781409469667
}

\section{Introduction}

This book is the result of several years of research in an international translation context with focus on law, language and communication. The editors organised a range of discussion sessions in Brazil and China between 2011 and 2013 where international scholars met and discussed their findings in order to develop new understandings relating to the translation of legal texts. The book contains 17 chapters, i.e. academic contributions, and is divided into two parts that deal with legal translation in theory and legal translation in practice, respectively. In addition, the book contains notes on editors and contributors, a foreword, an introduction, an afterword, and an index. This review concerns the 17 academic contributions with specific focus on their relevance to readers of Hermes.

\section{Part I: Legal Translation in Theory}

Mariusz Jerzy Golecki's contribution is called Translation vs. Decoding Strategies in Law and Economics Scholarship. This chapter deals with law and economics, is short, and the author does not relate his discussion and arguments to inter-lingual translation, nor does he provide references to literature on translation, theoretical, practical or otherwise.

In their contribution Cultural Transfer and Conceptualization in Legal Discourse Anne Wagner, King Kui Sin and Le Cheng focus on translabiliting, i.e. cross-cultural communication based on the matching of cultural elements in two languages instead of linguistic elements. Over four pages the authors attempt to describe the contamination of law by listing a range of references and citations to prove that "law is a material structure that carries symbols of everyday life" (p. 29). The next four pages describe legal discourse across disciplines and the contribution ends with three pages on cultural transfer of concepts. The authors conclude that translators will not be able to translate "the full load of the concept into the target language, which we can only achieve through meta-translational devices" (p. 39). For all this to be useful, the authors should have explained which meta-translational devices they refer to and how they can be used. My impression is that this contribution is made up of summaries of three different papers with the result that the topic is not very clear and difficult to trace throughout the text.

Chapter 3, Lost in Translation? Linguistic Diversity and the Elusive Quest for Plain Meaning in the Law, is written by Janet Ainsworth. The author discusses different challenges facing legal translators, such as those arising from the nature of language, the nature of legal language, the incommensurability of languages and the incommensurability of legal systems. Focus is on the equivalence of terms and Ainsworth supports her discussion with examples of translation challenges in the EU and how the principle of judicial purposive interpretation may affect translation of EU texts. The conclusion is that the "search for perfect equivalence in legal translation is [...] doomed to frustration" (p. 53), but that translators should strive for approximation. This chapter is a good introduction to legal translation with focus on terms and the author explicitly relates theory and practice to inter-lingual translation.

The contribution by Janny HC Leung, Translation Equivalence as Legal Fiction, examines which type of equivalence can best explain what it means that the target text has the same meaning as the source text and relates equivalence to the notion of legal fiction. She discusses legal fiction in relation to bilingual legislation in, e.g. Hong Kong, because a statutory legal text is presumed to have the same legal meaning in both languages, though it may be better to say that the two texts have the same legal effects. Leung concludes that the notions of textual and translational equivalence are akin to legal fictions and that translation equivalence is "hideous, structurally complex, 
and exercises widespread but unacknowledged power" (p. 68). The focus is on terms and target texts for the world at large, which is probably why the author argues that legal translators have "no control over reader experience and motivation" (p. 68). It would be interesting to see if an examination like this would come to the same conclusions if the theoretical basis is the skopos theory according to which legal translators can have knowledge of the experience and motivation of readers in that the target texts can be targeted to a specific reader or a specific group of readers; this applies to the translation of statutory texts as well as other legal text genres.

Chapter 5 is a contribution by Víctor Gonzáles-Ruiz and is called Trying to See the Wood Despite the Trees: A Plain Approach to Legal Translation. The author describes an approach to legal translation based on functional (skopos) theory and plain language principles and illustrates his arguments by a small experiment where an excerpt of an English employment contract is translated into two Spanish target texts, one using a traditional literal approach and one using a functional plain language approach. The result is that Spanish lawyers seem to prefer the functional plain language target text because it is easy to understand factually as well as linguistically. GonzálesRuiz bases his conclusions on replies to a questionnaire though it is not quite clear why the data support all conclusions because some of the questions are indirectly related to the factual and linguistic features of the source text, which the respondents apparently did not see; however, the use of a functional plain language approach to legal translation is interesting as it may result in target texts that are easy to understand linguistically as well as factually.

The contribution Minimal Unit of Legal Translation vs. Minimal Unit of Thought by Svetlana V. Vlasenko discusses how relevance theory can be used to identify what may be called units of legal translation as the basis for the product-oriented and the process-oriented side of translation. Different scholars define units of translation differently, and the author discusses the notions of referential equivalence, referential competence, referential range and referential portraits and gives interesting examples of how a reference approach can help translators identify minimum units of translation: "SL-texteme representing the plane of expression, the signifier, identifiable by the legal Translator as correlating with a certain set of his/her expert knowledge as part of the professional worldview at any given time" (p. 113). There is no doubt that reference theory can help legal translators as shown by Vlasenko; my only reservation is that she explicitly states that her understanding of translation is consistent with "the Peircean concept" (presumably triadic signs, but no further indication of what this refers to is given) but never refers to this again and generally refers to dyadic signs in her discussion.

Fernando Prieto Ramos' contribution is called Parameters for Problem-Solving in Legal Translation: Implications for Legal Lexicography and Institutional Terminology Management. The author describes legal communication as a dynamic concept and shows how the skopos theory of translation can facilitate translation at the micro-textual level. He proposes an integrative methodological model for legal translation including an analysis of the needs and expectations of receivers of target texts and argues convincingly that translators should consider applying the most adequate techniques for translating various text segments depending on the functions of target texts. In addition, Prieto Ramos identifies some requirements for translation-oriented legal lexicography of which several have been discussed in the lexicographical literature. For instance, Nielsen 2000 and Nielsen 2010a show how legal translation dictionaries can provide help to translate syntactical structures and textual conventions using different functional translation strategies, and Nielsen 2014 proposes a type of online dictionary that would seem to meet most of the requirements discussed by Prieto Ramos.

Catherine Way has written a contribution called Structuring a Legal Translation Course: A Framework for Decision-Making in Legal Translator Training and discusses the value of combining training approaches and developing a framework specifically for legal translation with a focus on decision-making and competences. Way convincingly argues that legal translation trainees should acquire competences enabling them to recognise factors that impact on translation 
decisions and proposes a framework within which lecturers can structure their teaching so that trainees can "acquire the information about alternatives, consequences, and events, and how they use this information" (p. 140). The framework encourages lecturers and trainees to focus on seven competences: communicative and textual, cultural, subject area, instrumental and professional, psycho-physiological, interpersonal, and strategic. Way's contribution is very educational in that it highlights an important aspect: legal translation is about much more than terms and comparative law. Furthermore, Way presents a teaching framework that appears logical and well-suited for trainees and points out that legal English is not geographically restricted to a few jurisdictions but is also in play when English acts as lingua franca in communication between persons from legal systems and cultures other than Anglophone ones.

\section{Part II: Legal Translation in Practice}

The contribution by Colin Robertson, EU Legislative Texts and Translation, gives a detailed description of the process, environment and context underlying the production (including translation and editing) of legislative texts in the EU as these factors help lawyer-linguists and translators identify pitfalls of grammar and syntax, syntax and meaning, terminological false friends and phrases in the target language vis-à-vis the source language. The work in the EU has generated terms and expressions that have no matches in the national languages as well as legislative texts that strictly follow standardised structures and rely extensively on standardised terms and phrases. Robertson clearly illustrates the need for cooperation between legislative drafters, translators, revisers and lawyer-linguists as they are all involved in the legislative process and points out that "translation crosses boundaries of language, concepts and culture" (p. 156). This chapter provides a good description of the context in which translators work in the EU and shows that translators need to have a good knowledge of the whole process of writing legislative texts and the environment in which they are created and apply. Robertson uses quite some space on describing and explaining the standardised layout of EU legislative texts in English in the last part of his contribution and his paper would have been even better if he had explicitly referred to inter-lingual translation issues instead of merely describing legislative texts in one language and leave it to readers to infer how this may affect translation.

The contribution by Łucja Biel, Phraseology in Legal Translation: A Corpus-Based Analysis of Textual Mapping in EU Law, examines the translation of phrasal editing units in EU legislative texts. The translation of selected standard phrases from English into Polish is examined and the results are compared with equivalent phrases in domestic Polish legislative texts. The findings show that there is considerable difference between those phrases with the highest occurrence in Polish legislative texts and those that occur most frequently in translated EU texts so that Polish EU texts contain untypical collocational patterns that show considerable interference from the English source texts, patterns that run counter to what Polish-speaking readers would expect. She concludes that "The departure from the TL conventions is unjustified" (p. 190) because the non-use of Polish phrasal conventions may lead to confusion and interpretive doubt, and because the translated EU legislation does not have the same formulaic rigour as Polish legislative texts; this may have a negative effect on communication. Anyone interested in these issues should read Biel (2014), which is an extension of her contribution and her analyses and discussion include the "Europeanisation" of legal Polish and an investigation into the nature of EU legal translation and its impact on national legal languages.

In his contribution Translating International Arbitration Norms into the Italian Language and Culture Maurizio Gotti examines how the adoption of the UNCITRAL Model Law on arbitration has been implemented in Italy through a mixture of translation and adaptation. This blended approach was chosen because the Model Law is intended to function in an international context whereas the Italian statute has to function in a national context and, therefore, "adjustments to the cultural needs and legal constraints" were necessary (p. 194). Gotti shows that the overall structure of the 
two laws differs because different legal frameworks necessitate emphasis on different aspects and topics in order for the Italian statute to function properly in its domestic setting. The two laws also differ linguistically in that the Model Law uses modals to express juridical obligations whereas the Italian law uses the present indicative to express legal obligations. Finally, Gotti shows that the Italian law uses both inter-textual and intra-textual references because it is embedded in a highly codified cultural and legal setting, while the Model Law only contains intra-textual references as it is not embedded in any general setting. The overall conclusion is that "legal translation in a multilingual/multicultural contest is greatly influenced by the linguistic constraints and legal traditions of the local communities to which the translation is addressed" (p. 205).

Celina Frade makes a similar comparative study in her contribution called Translating Domestic Legislation: A Comparative Analysis of English Versions of Brazilian Law on Arbitration. Frade compares two translations of the Brazilian law on arbitration based on the UNCITRAL Model Law on arbitration with particular focus on consistency and generic integrity relying on literal translation. The elements selected for the study include title, enacting clause, terms of authority, and collocations, and Frade shows that a mixture of approaches to translation can be identified. The translators have used "literal translation based on the generic features of the original version of the law in Portuguese; the appropriation of some generic features and conventions set forth in the UNCITRAL Model Law and the creation of unrelated legal neologisms to both legal systems (civil law x common law) and languages (Portuguese x English)" (pp. 220-221). The author concludes that translators of Brazilian legislation need multi-disciplinary training so that they do not make literal translations of all the elements examined resulting in texts that are susceptible of misinterpretation and not appropriate for informative purposes let alone legislative purposes.

Kayoko Takeda and Yasuhiro Sekine have written a contribution called Translation of Japanese Laws and Regulations. This contribution describes some of the most important challenges translators face when translating Japanese legislation into English as part of the Judicial System Reform and the Japanese Law Translation Database. The authors show how two periods of translation activities, the opening up of Japan to the rest of the world in the $19^{\text {th }}$ century and the occupation after the Second World War, affect legislative drafting and translation today. The Japanese authorities outsource translation tasks so that the lowest bidder usually wins the contract to translate one or more statutes into English. This has resulted in varying quality and "inconsistencies in document formats and the translation of legal terms and phrases" (p. 226) even though a Standard Legal Term Dictionary has been prepared and is freely available online. Takeda and Sekine identify three types of translation problems: the translations lack accuracy and consistency due to insufficient linguistic and factual knowledge on the part of translators; careless mistakes of grammar, spelling and conversion of numbers from Japanese and Chinese into Arabic numerals; and translators have problems with non-Japanese legal wordings that are remnants from the first translation era where Japanese law was greatly influenced by French and German law and legal language. The authors suggest that some of these problems can be solved by using translation memory systems, training courses for translators, and the introduction of plain legal language into Japanese legislation.

Rafat Y. Alwazna's contribution is called Important Translation Strategies Used in Legal Translation: Examples of Hooper's Translation of the Ottoman Majalla into English and has two distinct parts: the first is a description of translation theory, methods and strategies related to legal translation and the second part examines the translation methods and strategies used by a specific translator in three articles of the Ottoman Majalla, the book of sale. According to Alwazna, practical and theoretical translators of legal texts do not quite agree on which theories, methods and strategies are the best and some favour literal translation, others favour functional translation, while some believe that legal translation is a specific type of translation that does not fall within the general scope of translation theory. The structure and arguments in the descriptive part are mainly those found in Šarčević 1985. The analysis of the three translated articles of the Ottoman Majalla reveals that several strategies were used, in particular literal translation of terms, free translation 
when there is no one-to-one correspondence, translation by omission, translation by addition, change of foregrounding in the source text into backgrounding in the target text, description by definitions and explanations, and substitution. The analysis is very detailed and Alwazna clearly explains how and why the various strategies were used in the individual cases and concludes that the translator "has managed to produce the right legal result for proper and uniform application, which is the end result sought from the translation of laws" (p. 249) and that it is necessary to combine several translation strategies to achieve the purpose of the translation of legislation even within short passages of text.

The contribution by Lijin Sha and Jian Li, On the Translation of the Criminal Procedure Law of the PRC, examines two translations of the Criminal Procedure Law of the People's Republic of China by analysing six articles and their translation. The authors identify three major types of problem in connection with the translations, the first being informality in that several legal terms have been translated into non-legal terms. The second type of problem is the lack of accuracy as the translations examined contain terms and words that lead to ambiguous target text passages. Finally, the study reveals that the translators have not used legal terms consistently (one reason for this inconsistency may be due to collocational range and therefore acceptable, though this is not discussed). The authors conclude that "use of the literal approach as the conventional wisdom in legal translation is a double-edged sword that should be used with caution" (p. 261). It should be noted that the authors consistently use US English as a reference, so those familiar with e.g. the legal terminology in England and Wales might draw different conclusions than the authors.

Marta Chromá's contribution is called The New Czech Civil Code - Lessons from Legal Translation - A Case-Study Analysis. This contribution describes the preparatory stage of a project designed for the translation of the new Czech Civil Code into English and focusses on a comparative jurilinguistic analysis combined with a comparative conceptual analysis as necessary requirements for translating. The jurilinguistic analysis helps translators select the variety of legal English, e.g. that of England and Wales, Australia and Canada, and concerns modality, gender neutrality, presumptions in law, and the quasi-coordinator "rather than", while the conceptual analysis helps translators identify conceptual similarities and differences between the Czech legal system and their English counterparts, which is illustrated by the close examination of 15 terminological examples. The purpose of this elaborate preparation is to establish the proper basis for making translations of legislation that are "clear, unambiguous, formally transparent, consistent and semantically predictable" (p. 295). Chromá's contribution gives a clear and logical description of some of the theoretical and methodical issues translators of legislation should address in order to achieve good translations of statutory provisions into English, and by implication other foreign languages.

The final contribution, Multilevel Translation Analysis of a Key Legal Concept: Persona Juris and Legal Pluralism, is by Sandy Lamalle and deals with different concepts of persona juris in various legal systems as a basis for legal reasoning, logic and language and Lamalle emphasises the limits of its multilevel translation from a multi-focussed legal perspective. The author discusses the implications of vertical translation, i.e. transferral from one field of knowledge into another, and horizontal translation, i.e. translation into another legal language or system; examples are from Chinese, Indian and Muslim law, among others. Lamalle concludes that "the international language lacks interfaces, means of expression and approaches to the diversity of legal traditions" (p. 309).

\section{Assessment}

It is refreshing to see that so many of the contributors explicitly refuse to see legal translation as a purely terminological exercise. Translation of legal texts is not merely about concepts and terms but concerns the translation of texts in their entirety. For example, in her contribution Chromá refers to studies that show that up to $30 \%$ of the words in legal texts are terms and translators need methods, strategies and techniques to deal with the remainder $70 \%$ of the texts; this may be compared to the findings reported by Laurén (1993: 99-100) who found that terms account for 
less than $20 \%$ of the words in the legal texts studied. Furthermore, it is also refreshing to see that most contributors embrace functional translation strategies (skopos) and discuss some of the effects these may have. Legal translation should be seen as an activity that involves the translation of concepts and terms, the translation of language structures (e.g. collocations, phrases and routine formula), and the translation of textual/genre conventions (see e.g. Nielsen $2010 \mathrm{~b}$ for an example of how translation strategies can be applied to genre conventions in legal translation), and the task of translators is to identify challenges and available strategies and choose those solutions that have the highest information value to the intended readers of the translations. In order to do this, translators should have the necessary communicative, textual, cultural, subject area, instrumental, professional, psycho-physiological, interpersonal, and strategic competences.

There is one final issue I feel is necessary to address: there are more language errors, typos and layout mistakes than you would expect in a book like this. The following list contains just some of the offending passages but give a god impression of what you can find in the book: "interpreting is no exception Adhering to such a code"; "Positivism attempted to severe the relationship"; "to be more the exceptional than the rule"; "an approach which as recently been reflected"; "tools are required needed to"; "pose a particularly problem"; "can the translator appropriate of some conventions"; "maintain part the generic integrity"; "includes text-internal text-internal indicators"; "It can be explain by"; "believe that legal translation AS other areas of translation"; "unless the contrary intention appears $3 / 4$ ". In addition, several headings and subheadings have wrong numbers in chapter 3, and in chapter 16 you can find in-text references to examples A and B but none of the examples are labelled A and B. Proper copy-editing would easily have eliminated all those mistakes. The number of errors might be acceptable in proceedings but not in an academic book from an academic publisher. I may sound like a grumpy old man but if that is the case, I am not alone in thinking that this is an important issue in academic publishing:

\footnotetext{
"I don't think I'm really a pedant, but as a reviewer and examiner of academic writing I find myself put off (against my better judgement) by trivial errors of punctuation and so on. The trouble is that once I have been thus prejudiced against the writer, I am less likely to trust their judgement and interpretation of their evidence. Once the reader's trust in the writer is lost, then the writing loses all intellectual purchase upon the reader". (Bolton/Rowland 2014: 159)
}

The book reviewed is called Handbook of Legal Translation, which indicates a broad scope. As mentioned above, the predominant text type is legislation so the book has a rather limited scope in that respect. This does not mean that only translators of legislative texts can benefit from this book because several of the contributions address issues that are relevant to any kind of legal translation to various degrees. Again the title implies a wide variety of languages and this is partially true in that, with three exceptions, only English is treated as target language but several other languages act as source languages. As long as (potential) readers are aware of its apparently wide but actually limited scope, the book should be relevant for anyone working with and interested in inter-lingual legal translation, in particular chapters 3-16.

\section{References}

Biel, Łucja 2014: Lost in the Eurofog: The Textual Fit of Translated Law. Frankfurt am Main: Peter Lang.

Bolton, Gina/Rowland, Stephen 2014: Inspirational Writing for Academic Publication. London: Sage.

Laurén, Christer 1993: Fackspråk. Form, innhåll, function [Specialised Language. Form, content, function]. Lund: Studenterlitteratur.

Nielsen, Sandro 2000: Translation Strategies for Culture-Specific Textual Conventions in Bilingual Dictionaries. In Lexicographica. International Annual for Lexicography 16, 152-168.

Nielsen, Sandro 2010a: Specialised Translation Dictionaries for Learners. In Fuertes-Olivera, Pedro A. (ed.), Specialised Dictionaries for Learners. Berlin: de Gruyter, 69-82.

Nielsen, Sandro 2010b: Translational Creativity: translating genre conventions in statutes. In Vertimo Studijos 3, 23-35. Nielsen, Sandro 2014: Database of Legal Terms for Communicative and Knowledge Information Tools: In Mac Aodha, 
Máirtin (ed.), Legal Lexicography. A Comparative Perspective. Farnham: Ashgate Publishing Company, 153-175. Šarčević, Susan 1985: Translation of Culture-Bound Terms in Laws. In Multilingua 4(3), 127-133.

Sandro Nielsen 